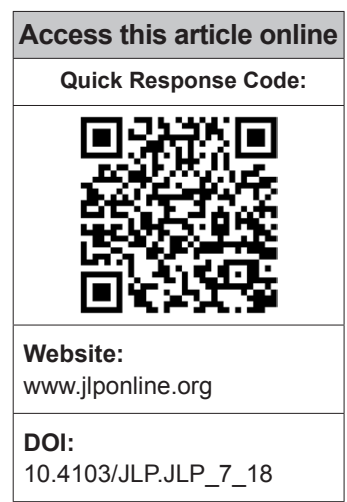

Department of Laboratory Medicine, Division of Clinical Microbiology and Molecular Medicine, All India Institute of Medical Sciences, Departments of ${ }^{1}$ Dermatology and Venereology and ${ }^{2}$ Medicine, All India Institute of Medical Sciences, New Delhi, India

Address for correspondence: Dr. Sarman Singh, Department of Laboratory Medicine, Division of Clinical Microbiology and Molecular Medicine,

All India Institute of

Medical Sciences,

New Delhi - 110029 , India.

E-mail: sarman_singh@ yahoo.com

Submission: 13-01-2018 Accepted: 14-05-2018

\title{
Seroprevalence of HSV-1 and 2 in HIV-infected males with and without GUD: Study from a tertiary care setting of India
}

\author{
Arshi Munawwar, Somesh Gupta ${ }^{1}$, Surendra Kumar Sharma ${ }^{2}$, Sarman Singh
}

Abstract:

BACKGROUND: Herpes simplex virus (HSV) infection is associated with an increased risk of both human immune deficiency virus (HIV) transmission and acquisition. However, in India, literature on HSV infections in in HIV-infected males has been scarce. The present study was carried out to assess the seroprevalence of these viruses in HIV-infected males, so as to provide a baseline data from India and report on HSV associated GUD prevalence in HIV infected males.

OBJECTIVE: The aim of the study was to estimate the seroprevalence of herpes simplex type 1 and 2 viruses in HIV-infected males with and without genital ulcers disease (GUD).

MATERIAL AND METHODS: It was a prospective study. We included a total of 351 male participants in this study. Among these 233 were HIV-infected and $118 \mathrm{HIV}$-uninfected males who served as controls. The seroprevalence was estimated, using HSV-1 and 2 type specific IgG and IgM antibodies by ELISA.

RESULTS: HIV-infected patients had a median age of $32 \pm 6.97$ years (interquartile range: 28-36). Of the 351 males, $25.92 \%$ (91/351) were infected with HSV-1 and HSV-2 both. The overall seroprevalence of HSV-1 singly infected, HSV-2 singly infected, and dual infection in HIV-infected males was $39.92 \%, 25.58 \%$, and $37.33 \%$ whereas in HIV-uninfected group the corresponding figures were $71.18 \%, 5.08 \%$, and $3.38 \%$, respectively. Seven of $233(3 \%)$ HIV-infected males were having incident HSV infection. GUD was reported in both HSV-1 and HSV-2 seropositive individuals.

CONCLUSIONS: Both HSV-1 and HSV-2 infections were found to be associated with GUD in HIV-infected patients. The prevalence of HIV-HSV co-infection among GUD patients is high.

Key words:

Genital ulcers disease, human immune deficiency virus/AIDS, herpes simplex virus-1, herpes simplex virus-2, seroprevalence

\section{Introduction}

T Terpes simplex virus (HSV) types 1 and 12 (HSV-1 and HSV-2) are common infections throughout the world. ${ }^{[1]}$ As a characteristic of these viruses the infection may remain latent for years and even lifelong. The HSV-1 is typically transmitted during childhood through nonsexual modes whereas HSV-2 is transmitted during

This is an open access journal, and articles are distributed under the terms of the Creative Commons Attribution-NonCommercial-ShareAlike 4.0 License, which allows others to remix, tweak, and build upon the work non-commercially, as long as appropriate credit is given and the new creations are licensed under the identical terms.

For reprints contact: reprints@medknow.com adulthood most commonly through sexual route. Although recent studies indicate that rarely both HSV-1 and HSV-2 can have overlapping modes of transmission. The age of primary infection with HSV-1 is increasing with the improvement in socioeconomic cultures. ${ }^{[2]}$

Considering that herpes viruses cause lifelong infection, though temporarily treatable, the infection cannot be eliminated

\footnotetext{
How to cite this article: Munawwar A, Gupta S, Sharma SK, Singh S. Seroprevalence of HSV-1 and 2 in HIV-infected males with and without GUD: Study from a tertiary care setting of India. J Lab Physicians 2018;10:326-31.
} 
by antiviral treatment, patients with HSV infection intermittently shed the virus. ${ }^{[3]}$ Genital ulcer disease (GUD)/Genital HSV infection is associated with HIV acquisition by $2-3$-fold and transmission by up to 5 -fold, accounting for $40 \%-60 \%$ of new infections in HSV-2-infected populations. ${ }^{[4]}$ Although HSV-1 is most often transmitted through nonsexual contact, recent data from some of developed countries indicate that a significant proportion of first-episode genital herpes is caused by HSV-1 ${ }^{\left[{ }^{[5]}\right.}$ In immunocompetent patients, not all infections lead to disease, and these patients may not seek the medical advice. However, in immunocompromised patients, not only this infection leads to disease manifestations, but in several cases, the infections can be very severe. Although in most cases, the lesions are diagnostic, serology remains the only practical method to assess the HSV infections in individuals without any relevant clinical history or presentation with lesions. ${ }^{[1]}$ Although several studies have been conducted in India most of these have focused on HSV-2 either in sexually transmitted disease (STD) settings or pregnant women as part of antenatal care. ${ }^{[6-11]}$ In the present study, we assessed the seroprevalence of HSV-1 and HSV-2 antibodies in HIV-infected male patients, stratified by age and associated risk factors.

\section{Material and Methods}

\section{Ethics statement}

The study was approved by Human Ethics Committee of the All India Institute of Medical Sciences (AIIMS), New Delhi, India (Ref. No. IEC/NP-260/2010). The study was carried out from September 2010 to December 2013, in the Division of Clinical Microbiology and Molecular Medicine, Department of Laboratory Medicine, AIIMS.

\section{Subject selection and testing of sera}

This prospective study was performed on 233 HIV-infected single patients' blood samples collected from nodal anti-retroviral treatment ART center of AIIMS (aged $>18$ years). In addition, 118 blood samples were collected from HIV uninfected individuals to serve as controls. These were spouses of women who visited the hospital for antenatal clinic, the voluntary blood donation, and the laboratory staff.

Male subjects $\geq 18$ years of age were recruited, after taking written informed consent to participate in the study. All individuals participating in this study were informed about the methodology and objectives of the research before signing the consent. A standardized questionnaire, administered to the participants by a trained interviewer, included questions about sociodemographic characteristics, sexual behavior, substance abuse including intravenous drug use, smoking/drinking habits, and history of STDs. STD was defined as self-reported or clinically confirmed past or recent history of any one of the following gonorrhea, syphilis, herpetic genital ulcers, and/or genital warts.

\section{Sample collection and testing of sera for herpes} simplex virus antibodies

Approximately, $5 \mathrm{ml}$ of blood sample was drawn through venipuncture and collected in a sterile plain vial. Serum was separated, coded with a unique patient identification number, and stored at $-80^{\circ} \mathrm{C}$ deep freezer until use. All sera samples were brought to room temperature before the test was carried out.

Antibody testing for HSV-1 and 2 was carried out in a batch of 90 samples. The sera were tested in parallel using anti-HSV-1 IgG ELISA (Euroimmun, Germany), anti-HSV-2-IgG (Euroimmun, Germany) and HSV-1/2 pool IgM ELISA (Euroimmun, Germany) assays as per the manufacturer's instructions. The assays used, as per the kit insert, are claimed to have $100 \%$ specificity as well as sensitivity for IgG tests. However, for the IgM, specificity is $93.15 \%$ and $95.7 \%$ for HSV-1 and 2, respectively. The anti-HSV-1 and HSV-2 ELISA (IgG) assays are intended for the qualitative determination of IgG class antibodies against HSV-1-specific glycoprotein C1 and HSV-2 specific glycoprotein $\mathrm{g} 2$ in human serum, respectively.

The cutoff value was calculated as per the manufacturer's instruction and optical density (OD) ratios were calculated by dividing the reading of each sample well by the cutoff value. Each OD ratio for the samples tested was interpreted as follows: $\mathrm{OD} \leq 1.0$ as negative and $\mathrm{OD} \geq 1.0$ as positive. All samples were tested at 1:100 serum dilutions. For those serum specimens with ambiguous test results, a repeat test was performed. If the result was still ambiguous, the sample was considered to be negative.

\section{Statistical analysis}

Data were analyzed using statistical package for the social sciences (SPSS) version 19. Demographic characteristics and risk behaviors were analyzed using descriptive statistics, i.e., median and interquartile range (IQR) for continuous variables, and proportions for categorical variables. Differences in variables were sought by Student's $t$-test or Chi-square/Fisher's exact test as appropriate. Initially univariate logistic regression analysis was conducted. $P<0.05$ was considered statistically significant.

\section{Results}

HIV-infected adult male patients had a median age of $32.0 \pm 7.36$ years (IQR: 29.0-38.0) and HIV-uninfected males had a median age of $30.0 \pm 5.89$ years (IQR: 27.0-35.0). 
Of the 233 individuals, 217 (93.13\%) were heterosexual with a median age of $32.0 \pm 7.18$ years (IQR: $24.25-37.75$ ) and only $16(6.86 \%)$ self-reported as either homosexual or bisexual with a median age of $34.0 \pm 6.75$ years (IQR: 28-38). One hundred and sixty-three (69.95\%) were naïve of ART while remaining seventy (30.04\%) were on ART.

The overall $\mathrm{CD} 4+\mathrm{T}$ cell counts ranged from as low as 16 to as high as 1719 cells $/ \mathrm{mm}^{3}$ with a median count of $403.0 \pm 261.4$ cells $/ \mathrm{mm}^{3}$ (IQR: 250.0-532.0). Individuals who were naïve of ART had CD4+ T-cell counts of $377.0 \pm 257.7$ cells $/ \mathrm{mm}^{3}$ (IQR: $253.0-536.0$ ) while those on ART had stable CD4+ T cell counts of $438.5 \pm 273.4$ cells $/ \mathrm{mm}^{3}$ (IQR: $\left.240.3-513.0\right)$. The difference in CD4+ $\mathrm{T}$ cell counts in ART naïve and ART-treated individuals was not statistically significant $(P>0.05)$. AIDS staging as per centers for disease control (CDC) (Atlanta, Georgia ,USA) classification of $163 \mathrm{HIV}$-infected males included in the study is described in Table 1.

Eighty of 233 (34.33\%) HIV-infected patients were referred from venereology clinic of AIIMS, New Delhi. Genital ulcers/lesions were reported by 77 (96.25\%) patients and genital warts/papules were reported by only $3(3.75 \%)$ patients. Thirteen of these $80(16.25 \%)$ individuals presented with recurrent GUD. However, in the control group, only $1.69 \%(2 / 118)$ had a history of GUD $(P<0.001)$.

The overall prevalence of antibodies against HSV-1, irrespective of HIV status, was $75.21 \%$ (264/351); (95\% CI: 70.35-79.64) in our cohort. Among these, 68.18\%; (95\% CI: 62.19-73.76) were HIV-infected while 31.8\%; (95\% CI: 25.64-37.15) were HIV-uninfected. When the prevalence of HSV-1 was analyzed on the basis of HIV status of individuals, the prevalence was $77.25 \%$ (180/233); (95\% CI: $71.32-82.47)$ in HIV-infected and 71.18\% (84/118), (95\% CI: 62.12-79.14) in HIV-uninfected males. The difference was not statistically significant. Among HIV-infected males, the prevalence increased with age, from $60 \%$ in individuals aged $<25$ years to $86 \%$ in older subjects $(P=0.0188)$.

The overall prevalence of antibodies against HSV-2 was 28.20\% (99/351), (95\% CI: 23.56-33.23). In HIV-infected patients, the prevalence was 39.91\% (93/233), (95\% CI: 33.57-46.51) while in HIV-uninfected individuals, it was $5.08 \%$ (6/118), (95\% CI: 1.89-10.73). HSV-2 prevalence in HIV-infected patients increased with age, from $23.3 \%$ in subjects aged $<25$ years to as high as $47.12 \%$ in $35-39$ years $(P=0.0796)$. The prevalence of HSV-2 in the control group was very low (5.08\%). Statistical analysis demonstrated significantly higher prevalence of HSV-2 antibodies in the HIV-infected male patients $(P<0.0001)$.

Only seven of 233 (3.0\%) subjects were positive for HSV-1/2 IgM. Among these four were also HSV-1 and HSV-2 IgG positive and of the remaining two were HSV-1 IgG positive. The average CD4+T cell counts of HSV-1/2 IgM-positive HIV-infected males was quite low; 204.6 cells $/ \mathrm{mm}^{3}$ as compared to their male counterparts positive for HSV-1/2 IgG; 409.3 and 400.8 cells $/ \mathrm{mm}^{3}(P<0.0001)$. Irrespective of HIV status, 91 of 351 males (25.92\%) were co-infected with HSV-1 and HSV-2. Among these 81 (95.60\%) were also HIV-infected (triply infected) and only four (4.39\%) were from the HIV-uninfected group. HSV coinfection was higher among married males as compared to unmarried men. The prevalence was significantly higher in heterosexual males. HSV-1 and HSV-2 coinfection was more prevalent in subjects who were heterosexual, were illiterate or attended elementary school, employed as unskilled labor, belonged to low-income group and consumed alcohol. Moreover, in HIV-infected males, no difference in HSV-2 prevalence was noted in symptomatic and asymptomatic subjects. The key determinants of HSV prevalence in HIV-infected males are shown in Table 2.

We also looked for the difference in HSV prevalence in ART naïve and those currently on ART. Fifty-eight out of $70(82.85 \%)$ subjects receiving ART were positive for HSV-1, thirty one $(44.28 \%)$ for HSV-2 and $29(41.42 \%)$ for both. These values were $122(74.85 \%)$, $62(38.04 \%)$, and $58(35.6 \%)$ for those who were not yet on ART. The difference, as expected was not statistically significant. Thirty $(42.85 \%)$ out of 70 individuals on ART reported a history of GUD; whereas 51 (31.3\%) out of 163 ART naïve individuals presented a history of GUD. The median CD4+ T cell counts of HIV-HSV-1 infected and HIV-HSV-1-HSV-2

Table 1: CDC classification of ART-naïve HIV-infected males ( $n=163)$

\begin{tabular}{lccc}
\hline CD4+T cell counts categories & \multicolumn{3}{c}{ Clinical categories } \\
\cline { 2 - 4 } & $\begin{array}{c}\text { A } \\
\text { Asymptomatic, } \\
\text { acute HIV, or PGL }(\%)\end{array}$ & $\begin{array}{c}\text { B } \\
\text { symptomatic conditions, } \\
\text { not A or C (\%) }\end{array}$ & $\begin{array}{c}\text { C } \\
\text { AIDS-indicator } \\
\text { conditions (\%) }\end{array}$ \\
\hline 2000 cells/ $\mu \mathrm{L}(n=47)$ A1/B1/C1 & $31(65.95)$ & $12(25.53)$ & $4(8.51)$ \\
$200-499$ cells/ $\mu \mathrm{L}(n=88)$ A2/B2/C2 & $40(45.45)$ & $32(36.36)$ & $16(18.18)$ \\
$<200$ cells/ $\mu \mathrm{L}(n=28)$ A3/B3/C3 & $6(21.42)$ & $9(32.14)$ & $13(46.42)$ \\
Total=163 & $77(47.23)$ & $53(32.52)$ & $33(20.25)$ \\
\hline
\end{tabular}

$\mathrm{HIV}=$ Human immune deficiency virus, $\mathrm{PGL}=$ Persistent generalized lymphadenopathy, AIDS = Acquired immune deficiency syndrome, $\mathrm{CDC}=\mathrm{Centers}$ for Disease Control 
Table 2: Demographic details of HIV-HSV co-infected males

\begin{tabular}{|c|c|c|c|c|}
\hline Characteristics $(n=233)$ & $\begin{array}{c}\text { All HSV } 1+v e \\
(n=180)(\%)\end{array}$ & $\begin{array}{c}\text { All HSV 2+ve } \\
(n=93)(\%)\end{array}$ & $\begin{array}{l}\text { HSV-1 alone+ve } \\
(n=93)(\%)\end{array}$ & $\begin{array}{c}\text { HSV-1 and 2+ve } \\
(n=87)(\%)\end{array}$ \\
\hline \multicolumn{5}{|l|}{ Age group } \\
\hline$<25(30)$ & $18(10.0)$ & $7(7.53)$ & $7(7.53)$ & $7(8.05)$ \\
\hline $25-29(43)$ & $35(19.44)$ & $19(20.43)$ & $11(11.83)$ & $18(20.68)$ \\
\hline $30-34(74)$ & $55(30.56)$ & $34(36.56)$ & $25(26.88)$ & 30 (34.49) \\
\hline $35-39(36)$ & $29(16.11)$ & $17(18.27)$ & $23(24.73)$ & $17(18.28)$ \\
\hline$>40(50)$ & $43(23.89)$ & $16(17.21)$ & 27 (29.03) & $16(18.40)$ \\
\hline \multicolumn{5}{|l|}{ Alcoholic } \\
\hline Yes (206) & $169(93.89)$ & $84(90.32)$ & 79 (84.95) & 78 (89.66) \\
\hline No (27) & $11(6.11)$ & $9(9.68)$ & $14(15.05)$ & $9(10.34)$ \\
\hline \multicolumn{5}{|l|}{ Education status } \\
\hline Uneducated (99) & 77 (48.33) & $50(53.76)$ & 77 (82.80) & 47 (54.02) \\
\hline Educated (134) & $103(51.67)$ & $43(46.24)$ & $16(17.20)$ & $40(45.98)$ \\
\hline \multicolumn{5}{|l|}{ Socioeconomic status } \\
\hline Low (170) & $132(73.33)$ & $63(67.74)$ & 70 (75.27) & $60(68.97)$ \\
\hline Middle (63) & $48(26.67)$ & 30 (32.26) & $23(24.73)$ & 27 (31.03) \\
\hline \multicolumn{5}{|l|}{ Employment } \\
\hline Employed (170) & $136(75.56)$ & 73 (78.49) & 68 (73.12) & $68(78.16)$ \\
\hline Unemployed (63) & $44(24.44)$ & $20(21.51)$ & $20(26.88)$ & $19(21.84)$ \\
\hline \multicolumn{5}{|l|}{ Marital status } \\
\hline Single (44) & $31(17.2)$ & $16(17.20)$ & $17(18.28)$ & $15(17.24)$ \\
\hline Married (189) & $149(82.8)$ & 77 (82.80) & 76 (81.72) & $72(82.76)$ \\
\hline \multicolumn{5}{|l|}{ Sexual preference } \\
\hline Heterosexual (217) & $168(93.33)$ & $84(90.32)$ & $90(96.77)$ & 78 (89.66) \\
\hline Homosexual (16) & $12(6.67)$ & $9(9.68)$ & $9(3.23)$ & $9(10.34)$ \\
\hline \multicolumn{5}{|l|}{ Mode of HIV acquisition } \\
\hline Sexual (208) & $164(91.11)$ & $86(92.47)$ & $84(90.32)$ & 80 (91.95) \\
\hline Others (25) & $16(8.89)$ & $7(7.53)$ & $9(6.78)$ & 7 (8.05) \\
\hline \multicolumn{5}{|l|}{ History of STD } \\
\hline Yes (81) & $70(38.89)$ & 49 (52.69) & $24(25.80)$ & $46(52.87)$ \\
\hline No (152) & $110(61.11)$ & $44(47.31)$ & $69(74.20)$ & $41(47.13)$ \\
\hline
\end{tabular}

HIV = Human immunodeficiency virus, STD = Sexually transmitted diseases, HSV = Herpes simplex virus

triply infected patients were 397 and 350 cells $/ \mathrm{mm}^{3}$. Median CD4+ T cell counts in HSV-2 IgG positive and negative individuals were 359 and 396 cells $/ \mathrm{mm}^{3}$, respectively. CD4+ T cell counts in HSV-1-HSV-2 dually infected symptomatic and asymptomatic subjects were 335 and 403 cells $/ \mathrm{mm}^{3}(P=0.0423)$.

\section{Discussion}

In this study, we mainly focused on determining the seroprevalence of HSV type 1 and type 2 in HIV-infected Indian male patients. In India, the typical route of HIV transmission has been through unprotected heterosexual intercourse. Male sexual activity outside marriage appears to be a driving force for the Indian HIV /STI epidemic. ${ }^{[12,13]}$ HSV-1 and HSV-2 are among the most common coinfections seen in individuals infected with HIV-1 and infection with HSV-2 is historically considered as a potential marker for high-risk behavior. ${ }^{[4,14]}$ The relationship between HSV-2 and HIV infection has been extensively studied in countries with high HIV burden such as sub-Saharan Africa ${ }^{[4]}$ and America ${ }^{[15,16]}$ but till submission of this manuscript, no such data are published from India. The study shows that not only HSV-2, but HSV-1 is also equally capable of causing severe morbidity and mortality, both in HIV-infected and in immunocompetent patients. ${ }^{[4,8,14]}$ In the past decade, investigations have amply documented the increase in the frequency of genital HSV-1 compared with genital HSV-2 infection. ${ }^{[2,5]}$ However, so far no such study has been published from this part of the world.

We found high HSV-1 prevalence in both HIV-infected and uninfected individuals. Similar findings have been reported from Western countries with a prevalence rate of $50 \%-70 \%{ }^{[17,18]}$ and as high as $99 \%-100 \%$ from Sub-Saharan African populations. ${ }^{[19,20]}$ In the present study, overall HSV-1 prevalence was $78.44 \%$. This value falls between the prevalence rates reported from the USA and Africa ${ }^{[17,20]}$ countries with high HIV burden. Moreover, it was observed that HSV-1 prevalence, increased consistently with age in HIV-infected males while in HIV-uninfected males a gradual decline in HSV-1 prevalence was observed. Similar findings have been reported in areas of the United Kingdom, where this proportion is $30 \%$ or more. ${ }^{[21]}$ 
The striking finding of this study was that triple infection of HIV, HSV-1, and HSV-2 was disproportionately high as compared to patients having infection of HIV with HSV-2 alone. ${ }^{[22,23]}$ The preexisting antibodies against HSV-1 increase the likelihood that incident HSV-2 infection will be asymptomatic by a factor of $2.6(P<0.001) .^{[2,14]}$ The findings of our study supports that in India, a proportion of genital herpes among men with high-risk sexual behaviour may be caused by HSV-1 infection also. This probably explains the relative predominance of HSV-1 and HSV-2 dual infections observed among men with GUD in this study.

The present study also contradicts expectations that viral GUD is caused predominantly by HSV-2. This can be justified by the fact that HSV-2 is transmitted mainly through sexual contact as opposed to HSV-1, which is commonly found in the orofacial region and is transmitted mainly by direct contact with saliva of asymptomatic carriers. However, in recent years a reversal in the distribution of these two viruses has been observed. ${ }^{[2]}$ The possible explanations for increasing trend of genital HSV-1 infection, include changes in sexual practices, such as oral sex associated with rise in sociocultural conditions. ${ }^{[2,5]}$

HSV-2 prevalence in Indian HIV-infected males was comparable to the prevalence seen in the population of countries with high HIV burden. ${ }^{[24]} \mathrm{HSV}-2$ prevalence in HIV-infected males showed an apparent decline in older subjects following peak levels in males aged in young males. ${ }^{[20]}$ Another important observation reported in the present study and as well as reported in several other studies is that majority of subjects with HSV-2 infection are coinfected with HSV-1. Since, HSV seroprevalence in high-risk subjects has shown remarkable consistency in the proportion of HSV-2-infected persons who harbor HSV-1 coinfection, as high as $70 \%-75 \% .^{[2,22]}$ Hence, it is conceivable that some of the reported adverse impact of HSV-2 coinfection among HIV-infected patients may be driven by or exacerbated by the presence of HSV-1 coinfection.

Another important finding of the study was that GUD was associated with lower CD4 + T cell counts in HSV-1 and HSV-2 co-infected patients, but not in subjects with HSV-1 associated GUD suggesting that de novo reactivation or freshly acquired HSV-2 infection occurs only when the immune suppression is more severe as compared to HSV-1. This is further supported by the findings of the Uganda Cohort ${ }^{[2,25]}$ and makes strong ground for early initiation of highly active antiretroviral therapy. The older age of acquisition of HSV-1 infection in HIV-infected patients as shown in this study and reported by others is an emerging phenomenon of epidemiological importance that may provide important opportunities to explore the significance of HSV-1-HIV dual and triple coinfection. Although the relationship between HSV and HIV incidence rates has not been established, these findings suggest that HIV prevention strategies targeting HSV coinfection should be considered in all HIV-infected patients. ${ }^{[14,26]}$

Herpes simplex virus prevalence remains high in India, among HIV-infected males with and without the GUD. The present study justify the continued use of antiherpetic therapy in syndromic management of HSVassociated GUD. The study reveals increase in the relative prevalence of HSV-1 associated GUD. The aetiology of ulcers without detectable HSV in a significant proportion of patients requires further research.

\section{Conclusion}

The prevalence of Herpes simplex viruses is high in India, among HIV-infected males with and without the GUD. The present study justifies the continued use of anti-herpetic therapy in syndromic management of HSV - associated GUD. The aetiology of genital ulcers without detectable HSV in a significant proportion of the patients requires further research and a apanel of investigations.

\section{Acknowledgments}

The authors would like to acknowledge the skillful help of Mr. Prem Shankar Mishra for his help in literature search and Mrs. Shalini Singhal Mrs. Omvati Vats, Mrs. Veena Balooni, Mr. Shakil Ahmad, Balbir Singh, Abhinav Kher, and Vinod Kumar. from the Division of Clinical Microbiology and Molecular Medicine, Department of Laboratory Medicine, AIIMS, New Delhi. Additionally, the authors would like to thank staff of ART Centre, AIIMS, New Delhi, India helping in subject recruitment and coordination for clinical support and procedures for study participants.

\section{Financial support and sponsorship}

The study was financially supported by Indian Council of Medical Research, New Delhi, India (Grant No: Indo-US/69/9/2010-ECD-II).

\section{Conflicts of interest}

There are no conflicts of interest.

\section{References}

1. Wald A, Ashley-Morrow R. Serological testing for herpes simplex virus (HSV)-1 and HSV-2 infection. Clin Infect Dis 2002;35:S173-82.

2. Tan DH, Kaul R, Walsmley S. Left out but not forgotten: Should closer attention be paid to coinfection with herpes simplex virus type 1 and HIV? Can J Infect Dis Med Microbiol 2009;20:e1-7. 
3. Tronstein E, Johnston C, Huang ML, Selke S, Magaret A, Warren $\mathrm{T}$, et al. Genital shedding of herpes simplex virus among symptomatic and asymptomatic persons with HSV-2 infection. JAMA 2011;305:1441-9.

4. Freeman EE, Weiss HA, Glynn JR, Cross PL, Whitworth JA, Hayes RJ, et al. Herpes simplex virus 2 infection increases HIV acquisition in men and women: Systematic review and meta-analysis of longitudinal studies. AIDS 2006;20:73-83.

5. Haddow LJ, Dave B, Mindel A, McPhie KA, Chung C, Marks C, et al. Increase in rates of herpes simplex virus type 1 as a cause of anogenital herpes in Western Sydney, Australia, between 1979 and 2003. Sex Transm Infect 2006;82:255-9.

6. Shepherd ME, Gangakhedkar RR, SahayS, Reynolds SJ, Ghate MV, Risbud AR, et al. Incident HIV infection among men attending STD clinics in Pune, India: Pathways to disparity and interventions to enhance equity. J Health Popul Nutr 2003;21:251-63.

7. Cowan FM, French RS, Mayaud P, Gopal R, Robinson NJ, de Oliveira SA, et al. Seroepidemiological study of herpes simplex virus types 1 and 2 in Brazil, Estonia, India, Morocco, and Sri Lanka. Sex Transm Infect 2003;79:286-90.

8. Kumarasamy N, Balakrishnan P, Venkatesh KK, Srikrishnan AK, Cecelia AJ, Thamburaj E, et al. Prevalence and incidence of sexually transmitted infections among South Indians at increased risk of HIV infection. AIDS Patient Care STDS 2008;22:677-82.

9. Schneider JA, Lakshmi V, Dandona R, Kumar GA, Sudha T, Dandona L, et al. Population-based seroprevalence of HSV-2 and syphilis in Andhra Pradesh state of India. BMC Infect Dis 2010;10:59.

10. Sgaier SK, Mony P, Jayakumar S, McLaughlin C, Arora P, Kumar R, et al. Prevalence and correlates of herpes simplex virus-2 and syphilis infections in the general population in India. Sex Transm Infect 2011;87:94-100.

11. Karad AB, Khade SL. Seroepidemiological study of herpes simplex virus type 2 infection in HIV positive patients, Delhi, India, 2007. Int J Med Public Health 2013;3:168-72.

12. Solomon S, Chakraborty A, Yepthomi RD. A review of the HIV epidemic in India. AIDS Educ Prev 2004;16:155-69.

13. Munawwar A, Sharma SK, Gupta S, Singh S. Seroprevalence and determinants of kaposi sarcoma-associated human herpesvirus 8 in Indian HIV-infected males. AIDS Res Hum Retroviruses 2014;30:1192-6.

14. Munawwar A, Singh S. Human herpesviruses as copathogens of HIV infection, their role in HIV transmission, and disease progression. J Lab Physicians 2016;8:5-18.

15. Hagan H, Jenness SM, Wendel T, Murrill CR, Neaigus A, Gelpi-Acosta C, et al. Herpes simplex virus type 2 associated with HIV infection among New York heterosexuals living in high-risk areas. Int J STD AIDS 2010;21:580-3.

16. Celum CL. The interaction between herpes simplex virus and human immunodeficiency virus. Herpes 2004;11 Suppl1:36A-45A.

17. Sanchez J, Volquez C, Totten PA, Campos PE, Ryan C, Catlin M, et al. The etiology and management of genital ulcers in the Dominican Republic and Peru. Sex Transm Dis 2002;29:559-67.

18. Allan PS, Das S. Prevalence of HSV-1/HSV-2 antibodies in HIV seropositive patients in Coventry, United Kingdom. Sex Transm Infect 2004;80:77.

19. Smith JS, Robinson NJ. Age-specific prevalence of infection with herpes simplex virus types 2 and 1: A global review. J Infect Dis 2002;186 Suppl 1:S3-28.

20. Wald A, Zeh J, Selke S, Warren T, Ashley R, Corey L, et al. Genital shedding of herpes simplex virus among men. J Infect Dis 2002;186 Suppl 1:S34-9.

21. Ross JD, Smith IW, Elton RA. The epidemiology of herpes simplex types 1 and 2 infection of the genital tract in Edinburgh 1978-1991. Genitourin Med 1993;69:381-3.

22. Romanowski B, Myziuk LN, Walmsley SL, Trottier S, Singh AE, Houston $S$, et al. Seroprevalence and risk factors for herpes simplex virus infection in a population of HIV-infected patients in Canada. Sex Transm Dis 2009;36:165-9.

23. Smit C, Pfrommer C, Mindel A, Taylor J, Spaargaren J, Berkhout B, et al. Rise in seroprevalence of herpes simplex virus type 1 among highly sexual active homosexual men and an increasing association between herpes simplex virus type 2 and HIV over time (1984-2003). Eur J Epidemiol 2007;22:937-44.

24. Sudenga SL, Kempf MC, McGwin G Jr., Wilson CM, Hook EW $3^{\text {rd }}$, Shrestha $S$, et al. Incidence, prevalence, and epidemiology of herpes simplex virus-2 in HIV-1-positive and HIV-1-negative adolescents. Sex Transm Dis 2012;39:300-5.

25. Duffus WA, Mermin J, Bunnell R, Byers RH, Odongo G, Ekwaru P, et al. Chronic herpes simplex virus type-2 infection and HIV viral load. Int J STD AIDS 2005;16:733-5.

26. Lisco A, Munawwar A, Introini A, Vanpouille C, Saba E, Feng X, et al. Semen of HIV-1-infected individuals: Local shedding of herpesviruses and reprogrammed cytokine network. J Infect Dis 2012;205:97-105. 